\title{
THE CONCEPT, EVOLUTION AND CHALLENGES OF DIGITAL LIBRARY DEVELOPMENT IN NIGERIA
}

\section{SHAIBU ADONA SADIKU}

\begin{abstract}
The adoption of information and communication technologies in information environment has made a radical change in information management. One of such revolutions has exhibited in the form of digital libraries. The evolution of digital libraries has ensured the emergence of global networked environment that has dramatically changed the status of libraries, their processes, service delivery as well as storage and retrieval systems. This paper examines the development of digital libraries, the concept, characteristics, funding, infrastructure, and ICT policy in Nigeria. The paper enumerates a number of challenges hindering the development of digital libraries in Nigeria and proffers some recommendations.
\end{abstract}

Key Words: Information and Communication Technology, Libraries; Digital LibrariesChallenges, Digital Library-Evolution

\section{Introduction}

The advent of Information and Communication Technology (ICT) has made libraries to undergo a paradigm shift from the traditional information to the technologically information driven environment. The adoption of information and communication technologies in information environment has made a radical change in information management. Libraries are storehouses of knowledge. The process of acquiring, storing, preserving and disseminating knowledge has changed considerably and libraries are becoming digital, where information resources are converted into digital format. Digital information services are now being provided to the user community in order to satisfy their information needs. The advent of electronic publication also led to the emergence of electronic resources, hence the emergence of digital libraries. A digital library is a very complex and dynamic entity which has brought phenomenal change in information collection, preservation and dissemination.

\section{The Concept of Digital Library}

Digital library means different things to different scholars. Despite dissimilarities between electronic library, virtual library and digital library, some scholars synonymously use the terms. A digital library, according to Borgman (1999), is a set of electronic resource and associated technical capabilities for creating, searching and using information. Arms (2000) defined digital library as a;

Managed collection of information, with associated services, where information is stored in digital format and access over a network. They are constructed, collected and organized by (and for) a community of users and their functional capabilities 
support the information needs and users of that community.

A digital library, according to Chowdury and Chowdury (1999), may be understood in different ways and may be named differently. Borgman (1999) drew attention to both complementarity and contradiction in various definitions. Terms such as electronic library, virtual library, hybrid library, gateway library, library of the future, and library without walls are used, sometimes synonymously with digital library, often to mean a subset, or a superset, of it, sometimes to signify a rather different concept depending on choices.

Digital Library Federation (1998) considers digital library as;

Organizations that provides the resources, including the specialized staff, to select, structure, offer intellectual access to, interpret, distribute, preserve the integrity of, and ensure the persistence, over time, of collections of digital works so that they are readily and economically available for use by a defined community or set of communities.

Some similarities identified to be common to all the definitions are that a digital library is a collection of digital information that has to be managed including its services and functions needed for its functionality.

\section{Architecture of Digital Library System}

Digital library system represents the richness and wealth of information which provides the unsophisticated users with flexible access to rich and complicated information. The key components of digital library system are user interface, repository, handle system and search system (Jange \& Angadi, 2001).

\section{User interfaces}

Both the pilot and the prototype libraries have two user interfaces: one for the users of the library, the other for the librarians and system administrators who manage the collections. Each user interface is in two parts. A standard Internet browser is used for the actual interactions with the user. This can be Netscape, Navigator, or Microsoft's Internet Explorer. The browser connects to client services, which provides intermediary functions between the browser and the other parts of the system. The client services allow the user to decide where to search and what to retrieve; they interpret information structured as digital objects; they negotiate terms and conditions, manage relationships between digital objects, remember the state of the interaction, and convert among the protocols used by the various parts of the system (Jange \& Angadi, 2001). 


\section{Repository}

Repositories store and manage digital objects and other information. A large digital library may have many repositories of various types, including modern repositories, legacy databases, and Web servers. The interface to this repository is called the Repository Access Protocol (RAP). Features of RAP are explicit recognition of rights and permissions that need to be satisfied before a client can access a digital object, support for a very general range of disseminations of digital objects, and an open architecture with well-defined interfaces (Jange \& Angadi, 2001).

\section{Handle system}

Handles are general purpose identifiers that can be used to identify Internet resources, such as digital objects over long periods of time and to manage materials stored in any repository or database. When used with the repository, the handle system receives as input a handle for a digital object and returns the identifier of the repository where the object is stored (Jange \& Angadi, 2001).

\section{Search system}

The design of the digital library system assumes that there will be many indexes and catalogues that can be searched to discover information before retrieving it from a repository. These indexes may be independently managed and support a wide range of protocols (Jange \& Angadi 2001).

\section{Characteristics of Digital Library}

Jebaraj and Deivasigimani (2003) highlighted the following characteristics of digital library:

- $\quad$ Contains permanent documents.

- $\quad$ Enables quick handling and momentary information.

- $\quad$ Based on digital technologies.

- Used by individuals working alone.

- $\quad$ The physical boundaries of data have been eliminated.

- $\quad$ Support communication and collaboration of information-seeking

- The linkages between the many digital library and information services are transparent to the end users

Irrespective of the characteristics possessed by today's digital library, it is hoped that the digital library of the future would develop a more comprehensive characteristics that will include;

- A comprehensive collection of resources important for scholarship, teaching and learning

- $\quad$ Readily accessible to all types of users, novices as well as the experienced 
- Managed and maintained by professionals who see their role as stewards of the intellectual and cultural heritages of the world.

- Digital library collections are not limited to document surrogates: they extend to digital artifacts that cannot be represented or distributed in printed formats.

\section{Functions of Digital Library}

Access to large amounts of information to users wherever they are and whenever they need it.

- $\quad$ Access to primary information sources

- $\quad$ Support multimedia content along with text

- $\quad$ Network accessibility on Intranet and Internet

- User-friendly interface

- Hypertext links for navigation

- $\quad$ Client-server architecture

- $\quad$ Advanced search and retrieval.

- Integration with other digital libraries.

\section{Evolution of Digital Library}

The first major landmark on the evolution of digital library came up in 1994, when it was announced that $\$ 24.4$ million of US federal funds would be dispersed among six universities for 'digital library' research (NSF 1994). The funding came through a joint initiative of the National Science Foundation (NSF), the Department of Defense Advanced Research Projects Agency (ARPA), and the National Aeronautics and Space Administration (NASA). The benefiting universities of the projects were Carnegie Mellon University, the University of California-Berkeley, the University of Michigan, the University of Illinois, the University of California-Santa Barbara, and Stanford University.

The projects according to (Hirtle 1999), helped to set in motion the popular definition of a 'digital library'. These projects were computer science experiments, primarily in the areas of architecture and information retrieval which was known as Digital Library Initiative-1 (DLI1). The DLI-1 grants were frequently criticized as exercises in pure research, with few practical applications

Though the projects were an exciting attempt to experiment digital collections, in no sense of the word did they resemble libraries. They had little or no service components, no custodianship over collections, no sustainability, no base of users, and no ethical traditions. This was termed "experimental" stage of digital library development. Because efforts during this experimental stage were the first to receive such widespread acknowledgment under the term 'digital library', they established a popular understanding of that term that has persisted for many years (Besser, 2004).

By 1996, social scientists who had previously worked with conventional libraries began to broaden the term 'digital libraries' (Bishop and Star, 1996; Borgman et al, 1996). But the real 
breakthrough came in 1998 when the US federal government issued a highly funded DL-2 awards to projects that contained some elements of traditional library service, such as custodianship, sustainability, and relationship to a community of users. At the same period, according to (Griffin, 1999), administrators of conventional libraries began to build serious digital components.

As librarians and social scientists became more involved in these digital projects, efforts moved from computer science experiments into projects that were more operational which was termed the 'developing stage of digital libraries'.

Libraries all over the world are now beginning to collect scholarship and material created by researchers and teachers on university campuses in electronic rather than printed forms. Large resources have been expanded on digital library developments. There are many efforts, projects and implementation of digital libraries, not only in advanced world but in many other countries as well.

\section{Digital Library Development in Nigeria}

Countries worldwide are struggling to establish digital libraries including African countries. However, funding obviously are problems of most African countries. Information environment as a result of this has had a demoralizing effect on the development of digital libraries in the continent. In his study of state of digitization in university libraries in SubSaharan Africa, Rosenberg (2006) found out that university libraries in Africa have progressed towards establishing digital library services at various speeds and levels but discovered that Africa depends much on external funding for the development of eenvironment which is not reliable in the first instance.

In Nigeria, the development of digital libraries is yet to be in a perfect stage compared with other developed world. For example, United States and some other developed countries, according to Abubakar (2009), commit more funds and efforts on digital libraries.

Nigeria is a country in West Africa with a population of 140,003,542 (Nigeria Census, 2006). Nigeria is the largest country in Africa and accounts for 47 percent of West Africa's population (World Bank, 2010). It occupies a landmass of about 923,768 square kilometers with over 274 ethnic groups. Nigeria is politically divided into six regions with 36 states and a total of 774 local government areas (LGAs).

A breakdown of the statistics available on Nigeria shows the following: More than 55\% of the people are female; the poverty rate is about $67.8 \%$, the majority of the people (70\%) live in the rural areas, and over sixty per cent of the young (0-15) are under the age of 15 . These statistics indicate that the majority of Nigerians fits the main focus of the Global Forum, which is to reach those who are yet to be reached (the class of the poor, the illiterate, women, the marginalized, and those living in remote areas) through one form of education or the other (whether formal or informal education). In particular, women and minority communities, such as nomads, fishermen, and unemployed youths are examples of these hitherto neglected communities in Nigeria (Jegede, 2002). Although very rich in natural 
resources, its economy has been considered to be backward. According to Obanya (2003), despite the fact that Nigeria has huge natural (agricultural and mineral) resources, two-thirds of its population struggles to survive on less than one United States dollar per day. The state of library and information environment in Nigeria is not very encouraging. This is because it is limited by high illiteracy rate, poor funding of education and libraries, lack of infrastructure, as well as large scale corruption that has eaten deep into the fabrics of society. These and many more factors tend to create a very hostile and unpleasant information environment in the country.

The above situation aptly presents a clear picture of the contemporary Nigerian society which is peculiar in nature, and within which libraries including digital ones are expected to function. Though a recent phenomenon, digital library development in Nigeria has in one way or the other received some attention from government and some other agencies. Ogunsola (2005) reported that the Federal Ministry of Education had embarked on the establishment of National Virtual (Digital) Library project with the aim of sharing locallyavailable resources with libraries all over the world using digital technology. The project was also devised to bolster the quality of teaching and learning in Nigerian schools. Other digital library projects initiated by government according to Gbaje (2007) are the National Board for Colleges of Education Virtual Library, the National Open University Library Project and the UNESCO Virtual Library Pilot Project initiated in 2003; none of these efforts had yielded any functional virtual (digital) library.

Apart from government interventions, the rapid growth of the telecommunications industry in Nigeria, added to some success story in digital library development in the country was reported by IT News Africa (2010) which stated that the Mobile Telephone Networks (MTN) Nigeria had successfully deployed and commissioned digital libraries in three (3) Universities in Nigeria. The three universities are the Ahmadu Bello University, Zaria, the University of Lagos and the University of Nigeria, Nsukka. The fourth one which has been billed for commissioning early this year is to be established at the University of Benin (Abubakar 2012). Virtual libraries were also established in some selected institutions across Nigeria. These projects were known as the World Bank Virtual Library projects.

\section{Challenges of Digital Library in Nigeria}

There are several challenges affecting the progress of digital library development in Nigeria and Africa in general. The complexity of digital library initiatives implies the existence of a wide range of challenges and barriers to its implementation and management. Some of these challenges are:

\section{Digital Divide}

This is one of the major challenges militating against the steady development of digital libraries in Nigeria. In fact, computer literacy is required for people to be able to take advantage of digital library applications. The digital divide refers to the gap between those who can effectively benefit from Information and Communication Technologies (ICTs) and those who cannot. According to Keniston (2000), digital divide is a problem of multiple 
dimensions that manifested into two parts; technical digital divide and social digital divide. While technical digital divide refers to availability of the infrastructure, the hardware and the software, social divide refers to the skills required to manipulate technical resources. Nigeria as a developing country is deficient in these aspects.

This gap, according to Smith (2002), can be filled by making computers available in public locations, such as grocery stores, post offices, libraries, and shopping malls. These measures may help in addressing the gap between those households that have access to the Internet and data services and those who do not.

\section{ICT Infrastructure}

One of the key challenges for the digital library development in Africa remains the widespread lack of infrastructure such as hardware, software, and standard bandwidth e.t.c. There is the urgent need for Nigerian libraries to double their efforts in seeking for adequate funding and commitment towards the development of digital libraries.

Information system networking is required to enable appropriate sharing of information and open up new channels for communication and delivery of services. Therefore, for a transition from traditional library system to digital library system, a design providing a uniform set of guiding principles, models and standards is required. In order to deliver digital library services, there should be an effective telecommunication infrastructure. Telecommunication infrastructure remains the backbone for the application of a wide range of communication and multimedia services.

\section{Inadequate Power Supply}

Another major constraint to digital libraries development in Nigeria is the inadequacy in electricity supply. Nigeria is a country characterized with constant power outage. This situation has negative effects on the development and implementation of digital library projects in Nigeria because digital library requires constant electricity to function.

\section{Instability in IT Policy}

Another major hindrance to the success of digital libraries development in Nigeria according to Abubakar (2012) is the inconsistent nature of the National Information Technology Policy that was approved in 2001. Diso (2008) observed that despite the national effort to promote ICTs that culminated in the setting up of the National Information Technology Development Agency (NITDA), which was saddled with the responsibility of implementing the National Information Technology Policy, nothing much has been achieved regarding the IT policy. This has an adverse effect to all digital library initiatives in Nigeria.

\section{Lack of Qualified Personnel and Training}

Lack of access to both ICT and education infrastructure in Nigeria is a major constraint on the development of digital libraries. The unavailability of human capacities that have technical skills, for designing, installation, implementation and maintenance of ICT 
infrastructure poses problems for digital library development. This problem affected most of the African countries, where the lack of qualified staff and inadequate human resources training has been a problem (UNPA\&ASPA, 2001). Therefore, there should be an interest and commitment in supporting ICT training and services as a strategy for addressing the digital gap in Nigeria.

\section{Right Technologies}

The inability of stakeholders to critically assess which kind of technology is appropriate for a specific purpose. Many foreign manufacturers flood the African market with all sorts of digital products, using incentives to coax government officials and managers of business as well as academic organizations to acquire their types of software and hardware. Many of these managers do not even know that a lot of products or brands exist for a given purpose. As observed by Ukonu Wogu, \& Obayi (2012), in one of the conferences organized by the Education Trust Fund (TETFund) at Nnamdi Azikiwe University, Awka, Anambra State, in 2006, for lecturers in tertiary institutions, one company came around to train participants on web-mining, but used the opportunity to introduce its own web-mining software which if adopted, would not be appropriate for the institutions information needs, and this was unknown to the participants. Therefore, there is the need for developing countries to always shop for products that suit their peculiarities in terms of meeting their needs.

\section{Conclusion}

In developing and maintaining digital libraries, it should be remembered that libraries are not merely collections of information; they have services, ethical traditions and values that are critical parts of their functions. Libraries cooperate with each other to serve the information needs of all categories of users and they are expected to sustain their collections so that they can serve users as much as possible. They protect their users' rights to access information at all time and they are expected to do so diligently with some degree of privacy as the case maybe.

\section{Recommendations}

Therefore, if Nigeria is to play an active role in global digital trends, the issue of digital library development should be made paramount in its activities. All hands must be on deck to overcome some of the major challenges and frustrations facing the development of effective digital libraries. As it stands now, certainly a lot of attention needs to be paid to its developments. There is the need for partnership among libraries and for the development of a knowledge base forum comprising experts to act as core for the development of digital libraries in Nigeria.

It is obvious that there is a need to develop viable and sustainable broadband infrastructure for Nigeria and in addition, it is important to have adequate funding made available for the acquisition of appropriate hardware, software and training. 
The Nigerian Government should give absolute priority to the information sector which is one of the key sectors for societal development. Adequate funds should be provided to libraries for their development and functioning. Also, all Digital Library Initiatives (DLI) should be wholeheartedly supported. The country cannot afford to be continuously left behind in this fast era of global change.

There is the need to involve information professionals, especially librarians in all digital library initiatives. It is also important to intensify the training of such professionals in the area of ICTs, particularly on digitization, digital technologies, as well as web-based skills, which are all essential prerequisites for digital library services and developments.

The Nigerian Government should as a matter of urgency address the problems of infrastructure such as steady electricity supply and stable telecommunication networks across the country. Also, emphasis should be given to the accessibility and subscription of electronic information resources, as well as free web-based information items by digital libraries in Nigeria.

\section{Reference}

Abubakar, A. B. (2009). Education for Digital Libraries in Asian countries. Paper Presented at the Asia-Pacific Conference on Library and Information Education and Practice, (p. 459).

Abubakar, Bappah Magaji (2012). Digital Libraries in Nigeria in the Era of Global Change: A Perspective of the Major Challenges. Retrieved from dspaces.uok.edu.in/ojs/index.php/crdr/article/viewFile/5/15 on 16/07/2014

Bishop, Ann and Susan Leigh Star (1996). Social Informatics for Digital Library Use and Infrastructure. In Besser (2004.), the Past, Present and Future of Digital Library. Retrieved on 19 July, 2014 from http://www.digitalhumanities.org/companion/

Borgman, C. L. (1999). What are Digital Libraries? Competing Visions.Information Processing and Management, 35 (3): 227-43.

Borgman, Christine, et al. (1996). Social Aspects of Digital Libraries, Final Report to the National Science Foundation. Digital Libraries Initiative Retrieved on 19 July, 2014 fromhttp://dli.grainger.uiuc.edu/national.htm.

Chowdury, G. G. and S. Chowdury. (1999). Digital Library Research: Major Issues and Trends, Journal of Documentation, 55 (4): 409-48.

Dass, Sarjiwan and Yadav, S. K (2011). The Concept of Digital Libraries and an Unavoidable Need in Today's World. Retrieved from sarjiwanpublications.blogspot.com/2011/02/declaration.html on 14/7/2014 
Diso, L. I. (2008). Mobile Service Providers and M-Learning in Nigeria: Mobility in a Contracting Space. International Journal of Interactive Mobile Technologies (IJIM), 2 (1): 40-45

Gbaje, E.S. (2007). Challenges of Implementing Virtual Library for Higher Institutions in Nigeria. A Paper Presented at the Conference of the Nigerian Library Association (NLA) (p.42).

Hirtle, Peter (1999). A New Generation of Digital Library Research. Editorial. D-Lib $\begin{array}{llllll}\text { Magazine 5: } & \text { 5-8 } & \text { retrieved } & \text { July, } & \text { from }\end{array}$ http://www.dlib.org/dlib/july99/07editorial.html.

Jange, Suresh and Angadi, Mallikarjun (2001). Digital Libraries: An Overview. Retrieved on 14/7/2014 from eprints.rclis.org/4975/.

Jange, Suresh and Angadi, Mallikarjun (2001). Digital Libraries: An Overview. Retrieved on 14/7/2014 from eprints.rclis.org/4975/

National Science Foundation (NSF) (1994). NSF Announces Awards for Digital Libraries Research; \$24.4 Million to Fund Advanced Research and Technology Development by Teams from Universities, Industries and Other Institutions. Retrieved July, 2014 from http://elib.cs.berkeley.edu:80/admin/proposal/nsf-press-release.html.

Ogunsola, L.A. (2005). Nigerian University Libraries and the Challenges of Globalization: The Way Forward. Journal of Social Science, 10 (3): 199-205

Rosenberg, D. (2006). Towards the Digital Library in Africa. The Electronic Library, 24 (3): 289-293.

Ukonu, Michael, Wogu, Joseph and Obayi, Paul (2012). Problems and Challenges Facing the University of Nigeria Undergraduate Students in the Use of the UNN Digital Library. IOSR Journal of Humanities and Social Science, 3 (2): 04-12.

World Bank Report on Nigeria (2010). Nigerian Investment.com. Retrieved July 12, 2014 from http://www.nigerianinvestments.com/index. 